STUDI

FRANCESI

\section{Studi Francesi}

Rivista quadrimestrale fondata da Franco Simone

171 (LVII | III) | 2013

FRANCO SIMONE E LA STORIOGRAFIA LETTERARIA -

Atti della giornata di studi nel centenario della nascita promossa dall'Accademia delle Scienze di Torino in collaborazione con «Studi Francesi» Torino - 24 maggio 2013

\title{
Bronwen Martin, The Fiction of J. M. G. Le Clézio. A Postcolonial Reading
}

\section{Chiara Denti}

\section{(2) OpenEdition \\ 1 Journals}

\section{Edizione digitale}

URL: http://journals.openedition.org/studifrancesi/2892

DOI: 10.4000/studifrancesi.2892

ISSN: 2421-5856

\section{Editore}

Rosenberg \& Sellier

\section{Edizione cartacea}

Data di pubblicazione: 1 dicembre 2013

Paginazione: 650

ISSN: 0039-2944

\section{Notizia bibliografica digitale}

Chiara Denti, « Bronwen Martin, The Fiction of J. M. G. Le Clézio. A Postcolonial Reading », Studi Francesi [Online], 171 (LVII | III) | 2013, online dal 30 novembre 2015, consultato il 18 septembre 2020. URL : http://journals.openedition.org/studifrancesi/2892 ; DOI : https://doi.org/10.4000/studifrancesi.2892

Questo documento è stato generato automaticamente il 18 settembre 2020.

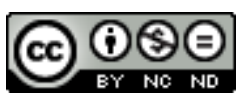

Studi Francesi è distribuita con Licenza Creative Commons Attribuzione - Non commerciale - Non opere derivate 4.0 Internazionale. 


\title{
Bronwen Martin, The Fiction of J. M. G. Le Clézio. A Postcolonial Reading
}

\author{
Chiara Denti
}

\section{NOTIZIA}

Bronwen Martin, The Fiction of J. M. G. Le Clézio. A Postcolonial Reading, Berne, Peter Lang, 2012 («Modern French Identities»), pp. 193.

1 Dal conferimento del premio Nobel per la letteratura l'opera e la figura di J. M. G. Le Clézio, a lungo trascurate, sono al centro di numerosi contributi che ne mettono in rilievo tanti e nuovi aspetti. Il saggio di Bronwen Martin testimonia questa inaspettata fioritura di interesse anche al di fuori dello spazio francese e propone una lettura della narrativa di Le Clézio in chiave postcoloniale. Attraverso un'analisi puntale e cronologica dei testi presi in esame, lo studio ricostruisce l'evoluzione del pensiero postcoloniale dello scrittore a partire dalla prima opera narrativa Le Procès-verbal (1963) fino al recente Révolutions (2003). La studiosa chiarisce nell'importante introduzione quale significato sia attribuito a "postcoloniale" e quali accezioni questo termine problematico assuma nel corso del lavoro. I tre modi in cui viene declinato il termine definiscono, tra l'altro, i principali assi di riflessione su cui si innesta il lavoro (critica del pensiero filosofico occidentale, denuncia della dominazione coloniale e del neocolonialismo che segna l'età contemporanea). Lo studio adotta un criterio cronologico, quello che meglio coglie ed estrapola la linea di continuità fra i testi, accomunati da una critica serrata del passato coloniale e del presente neocoloniale.

La prima sezione, interamente riservata ai romanzi giovanili, si concentra in particolare sul romanzo d'esordio a cui viene dato ampio spazio non solo perché qui ha inizio il percorso postcoloniale di Le Clézio, ma anche per le profonde assonanze con Révolutions, che ne riprende e sviluppa molte tematiche. Segue poi l'analisi di altri tre romanzi (Le Livre des fuites, Désert e Poisson d'or), scelti per preparare e porre una base all'accurato close reading di Révolutions, da più parti riconosciuto come il romanzo più 
riuscito e sovversivo dell'autore. È nei restanti capitoli, racchiusi nella seconda sezione, che il capolavoro di Le Clézio è sondato ed esplorato così da portare alla luce l'enorme varietà di temi che lo attraversano.

3 L'analisi testuale condotta sui romanzi è continuamente nutrita da illuminanti richiami intertestuali ad autori, opere e punti di vista a cui l'opera di Le Clézio è indissolubilmente legata. È proprio grazie ad essi che le idee dello scrittore vengono collocate all'interno del vasto insieme di prospettive che compone la teoria postcoloniale, acquisendo spessore e forza. Il pensiero di Le Clézio pare perfettamente intonato alle tesi anticolonialiste formulate da Sartre, Césaire e Fanon, così come alle recenti riflessioni di Paul Gilroy e Étienne Balibar sulle forme contemporanee di discriminazione e dominazione che ricalcano gli schemi di un tempo. Il saggio ha l'indiscusso merito di analizzare la narrativa di Le Clézio attraverso una lente inedita capace di aprire nuovi stimolanti percorsi interpretativi, ma anche, e soprattutto, di mostrare come nelle sue pagine entrino problematiche che incrociano dibattiti attuali e scottanti, quali quelli sull'identità, la cittadinanza e l'interculturalità. 